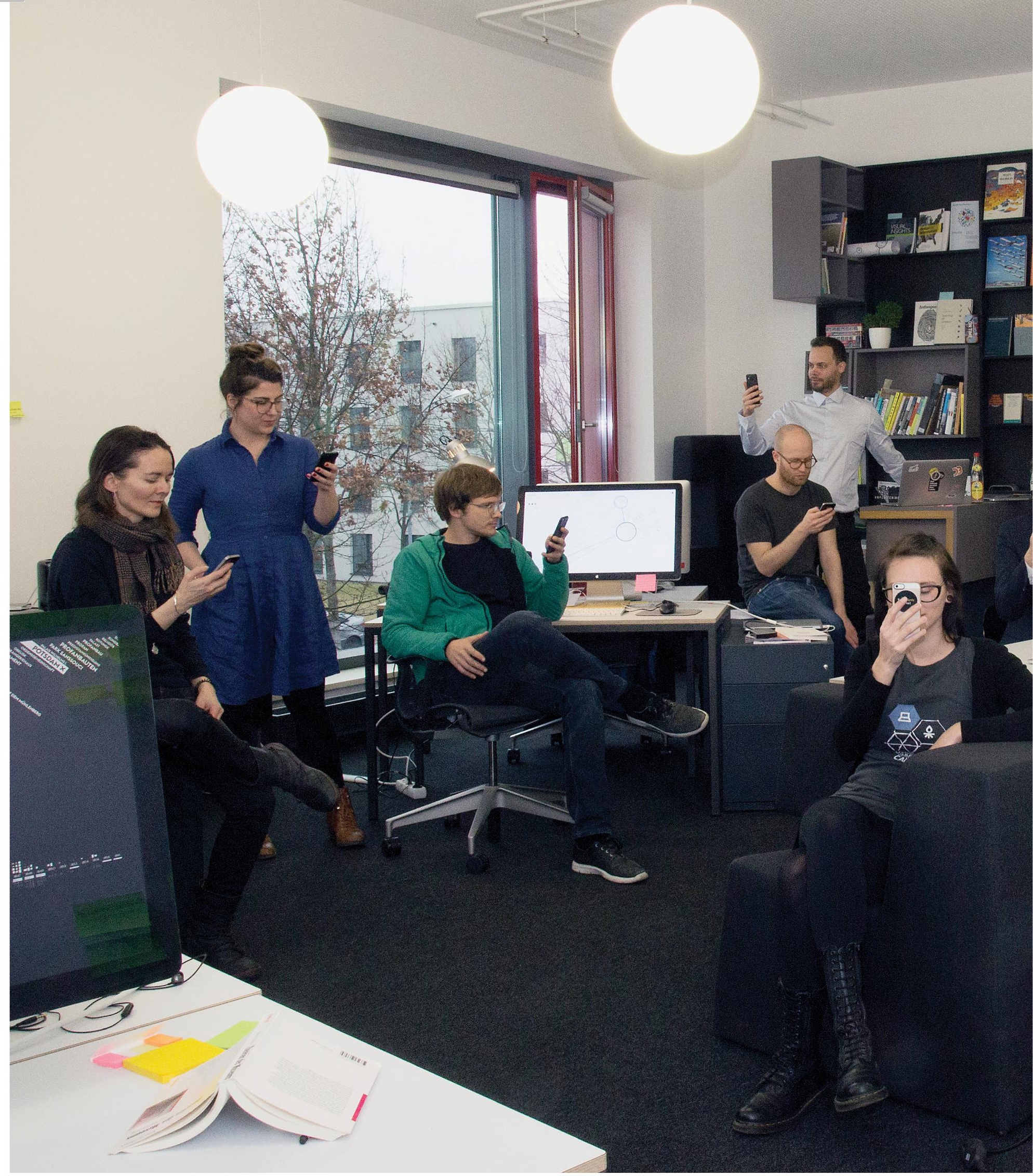




\section{Urban Complexity Lab}

As told by Marian Dörk, Boris Müller, Stephanie Neumann,

Johannes Herseni, Katrin Glinka, Katja Dittrich,

Christopher Pietsch, Linda Freyberg, and Jan-Erik Stange

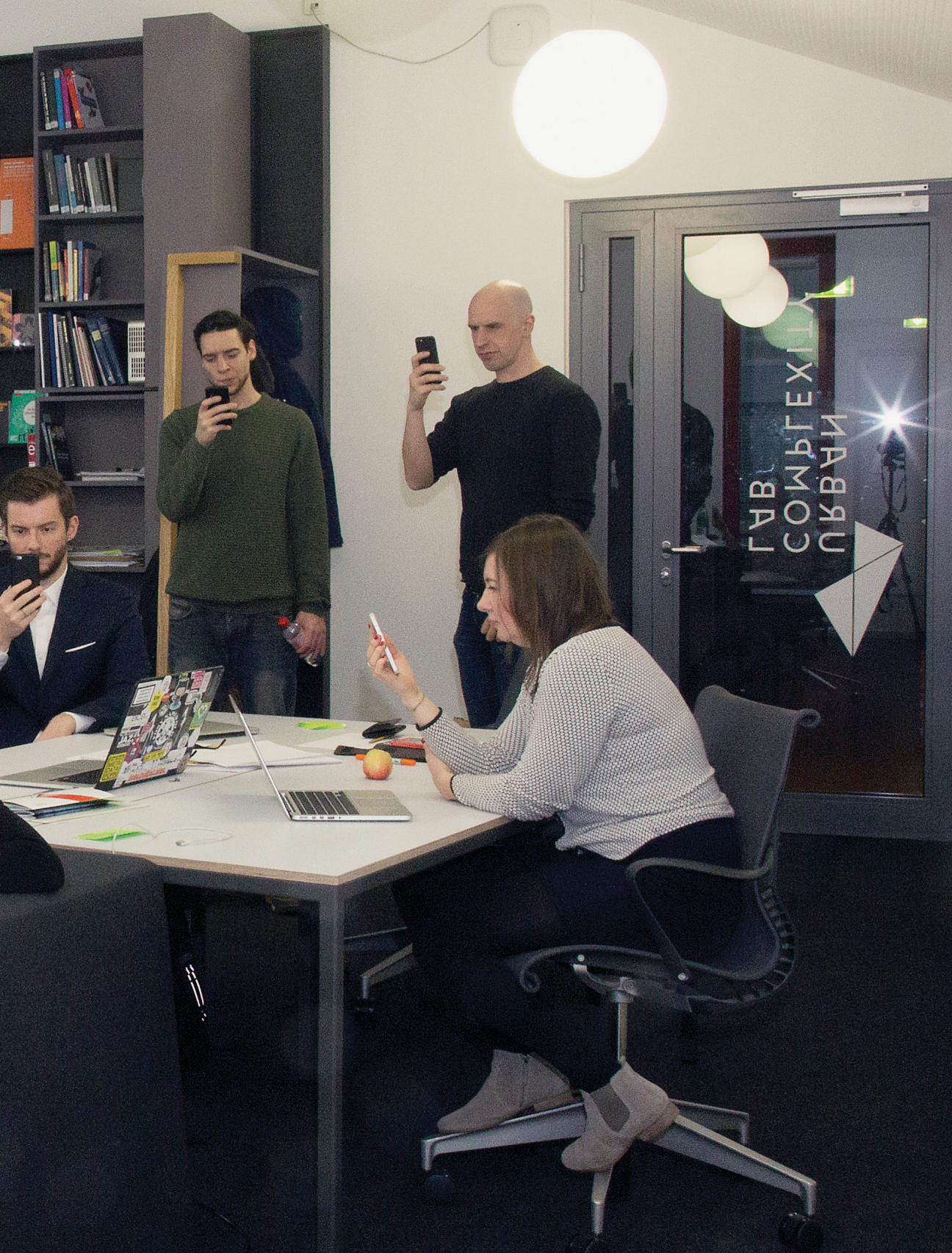

The large displays are just for decoration The lab is a mobile-first workplace.
H

ow do you describe your lab to visitors?

The Urban

Complexity Lab is

an interdisciplinary

research space at $\mathrm{FH}$

Potsdam (University

of Applied Sciences) situated between design, computer science, and the humanities. Our work largely revolves around information visualization and interaction design with a particular focus on the challenges and questions arising from cultural and urban transformations. Our mission is to develop a responsible approach toward data and to study innovative methods for interactive visualization to make sense of complex datasets, especially in the contexts of digital humanities and smart cities.

What is a unique feature of your lab?

Within the university, the lab is a collaboration between the Department of Design and the Urban Futures Institute for Applied Research. At the junction of design teaching and visualization research, we strive to have an impact in both academia and the wider world of practice. For the physical and social space of the lab, our ambition is to cultivate a stimulating environment for an interdisciplinary community of designers, developers, and researchers that reaches out to citizens, cultural institutions, administration, and businesses. We are keen to share our work with the broader public via social media, online demos, and events such as exhibitions, and with our academic peers through conferences and journals.

\section{How many people are in the lab, and} what is the mix of backgrounds and roles? Our group distinguishes itself by being particularly diverse with regard to discipline and levels of experience. We are currently nine researchers with backgrounds in interaction design, computer science, cultural studies, and information science. From undergraduate researchers to professors, our team also intentionally features a broad mix of seniority. Based on our teaching in the design program, we regularly invite B.A. and M.A. students, as well as recent alumni, to work on their own research projects or get involved in ongoing research initiatives in the lab. Over the brief course of the lab's existence (just 


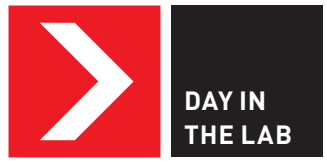

$\rightarrow$ A room and a team.

The lab is a physical and social space.
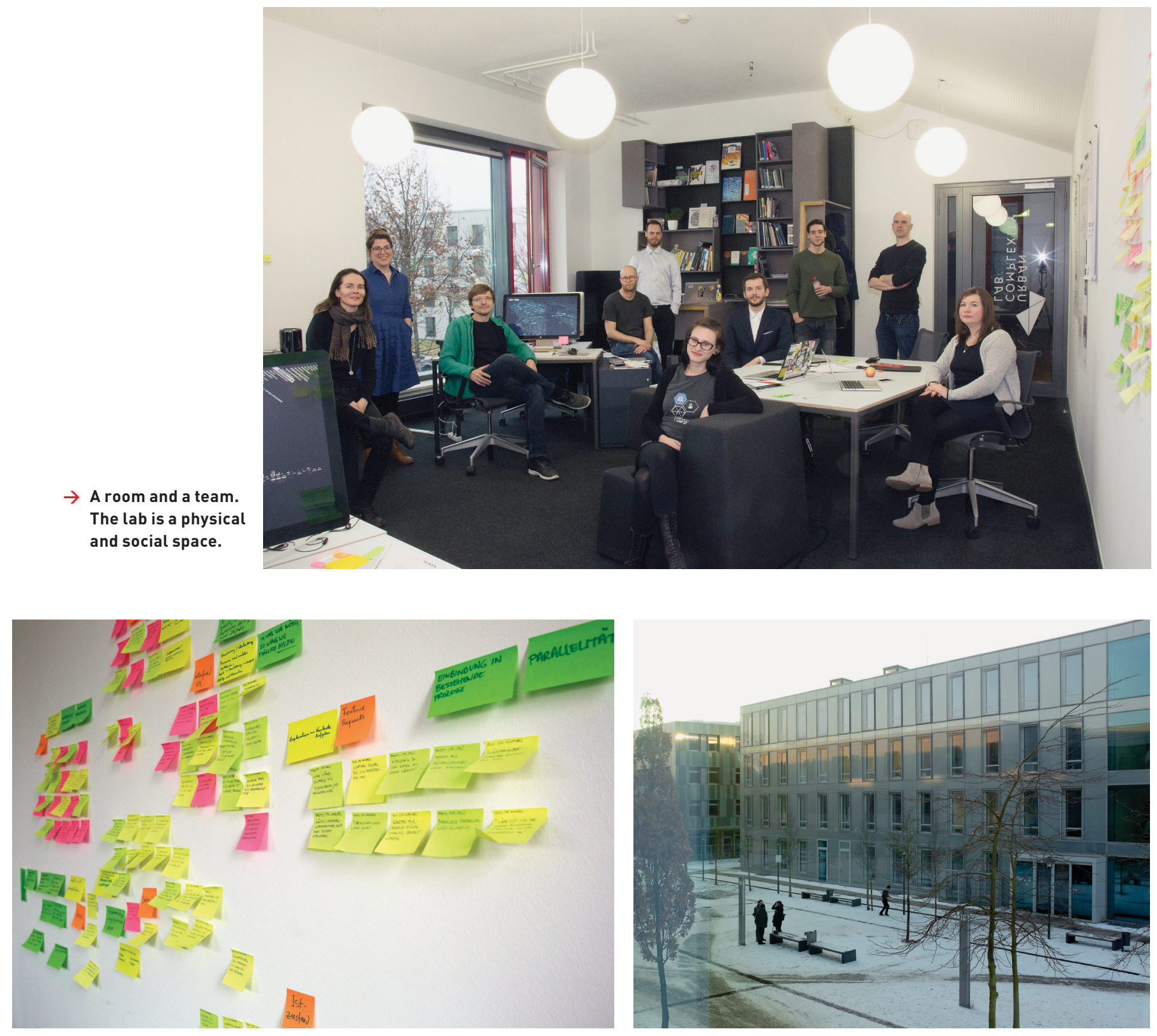

$\rightarrow$ Mapping out the aims of a research project (half a year agol. Surprising how sticky they are.

$\rightarrow$ Giovanni Profeta visiting us from Density Design in Milan. Here, giving an overview of his Ph.D. topic.

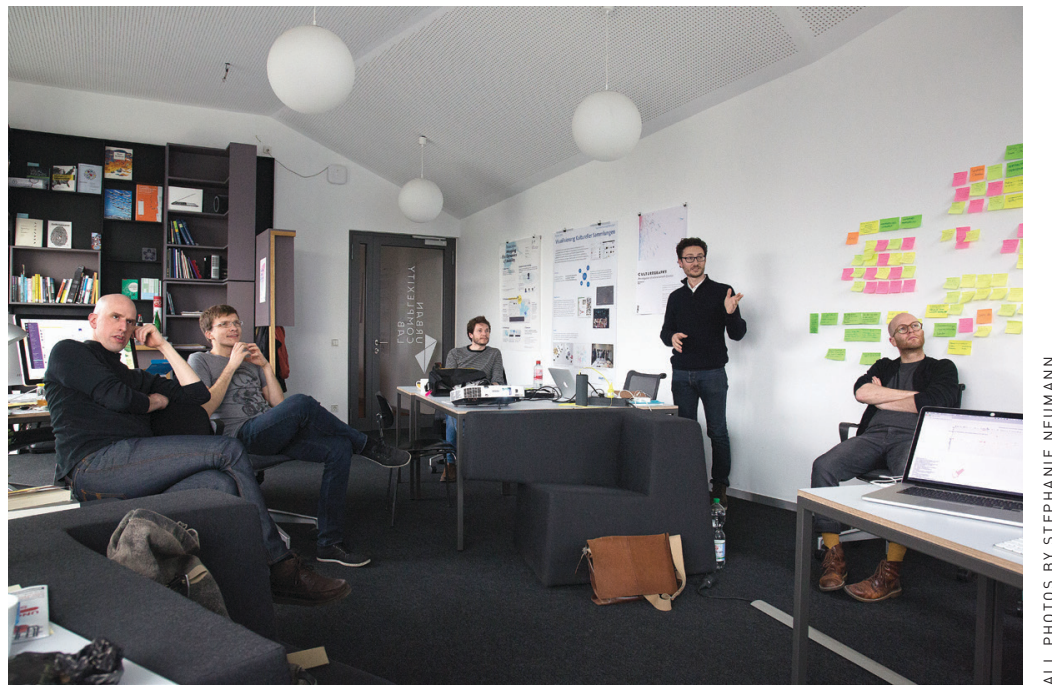



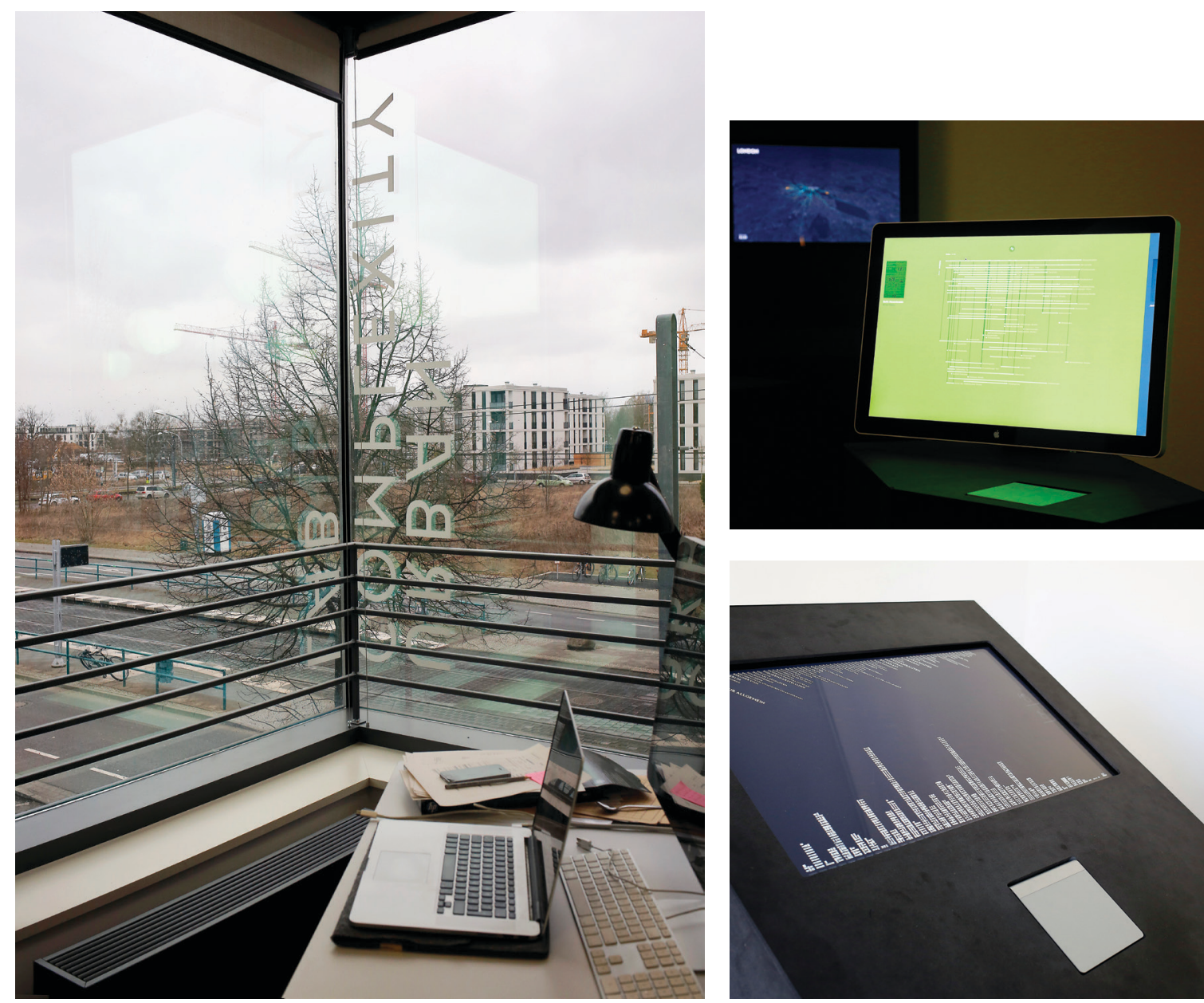

$\rightarrow$ City visualizations on display at the exhibition "Streams and Traces-Mapping the Ephemeral City."

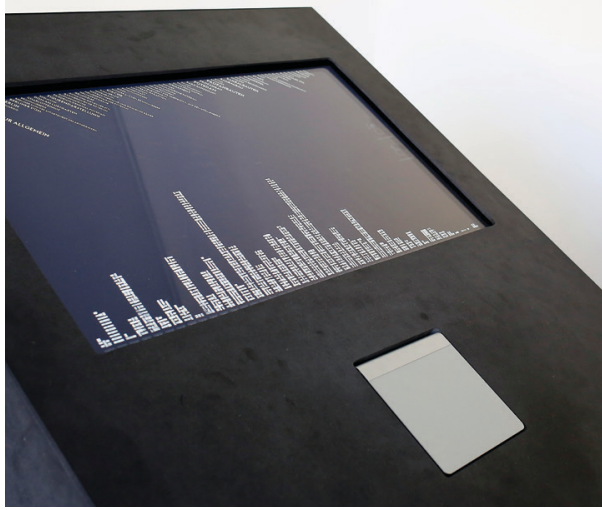

$\rightarrow$ Visualization of a cultural collection on display at the exhibition "Streams and Traces-Mapping the Ephemeral City."

$\rightarrow$ The view of the tram stop and our suburban neighborhood.

over two years), we have undertaken several successful research projects with students that were presented at international conferences.

\section{Briefly describe a day in the life of} your lab. Every day is different. First of all, activity levels vary over the course of a week. The lab is the busiest in the middle of the week. Mostly we try to work quietly in the lab but also regularly gather in smaller groups or teams in our meeting room just next door. Nonetheless, we often exchange ideas, feedback, and advice in the group and of course also like to chat, banter, and share a cup of coffee. Since many of our lab members also teach or cooperate with other departments and colleagues on campus, we do have quite a lot of fluctuation throughout the day. When we have a visitor in the lab, there are usually demo sessions lined up for them to check out current prototypes or studies. Wednesday has emerged as the meeting day with project and lab updates, as well as one-on-one meetings. On Fridays, the lab can be a calm place, which is when most of us are working from home, the library, or a cafe. Especially when working remotely we rely on Slack to coordinate work, exchange lab gossip, and upload GIFs.

\section{What is one feature of your lab that} you could not do without? We enjoy working in such a light and friendly room and often get rewarded with a stunning view of the sunsetespecially in wintertime - just above the tram rails that run past the university. Since most of us live in Berlin and commute to Potsdam, we couldn't do without the tram, at least during the cold and rainy months. During spring and summer, many of us commute by a combination of bike and train, which allows us to take a beautiful route along the Havel river and through the woods on our way back to the city, and maybe even stop for a quick swim. The lab has two unique acoustic features that remind us not to work too late. Because the room was originally conceived as part of the university library, there is a speaker on the ceiling that rings in a loud tone every evening just before the library closes. And then there is the Slack-tospeech bot \#raum111 that reads out whatever is being entered in the Slack channel and scares us when we're working late or are alone in the lab.

\section{What is one feature of your lab you} want and do not have? Some of us would love to have a lab dog, but Boris says no. $\mathrm{He}$ is also averse to plants and shrubs.

\section{How would you describe how people} interact in your lab? It's a bit like a little family. As a team we share critical yet constructive feedback to help each other in our respective research projects.

Beside our cordial relationships with each other, we are the masters of irony.

http://uclab.fh-potsdam.de 